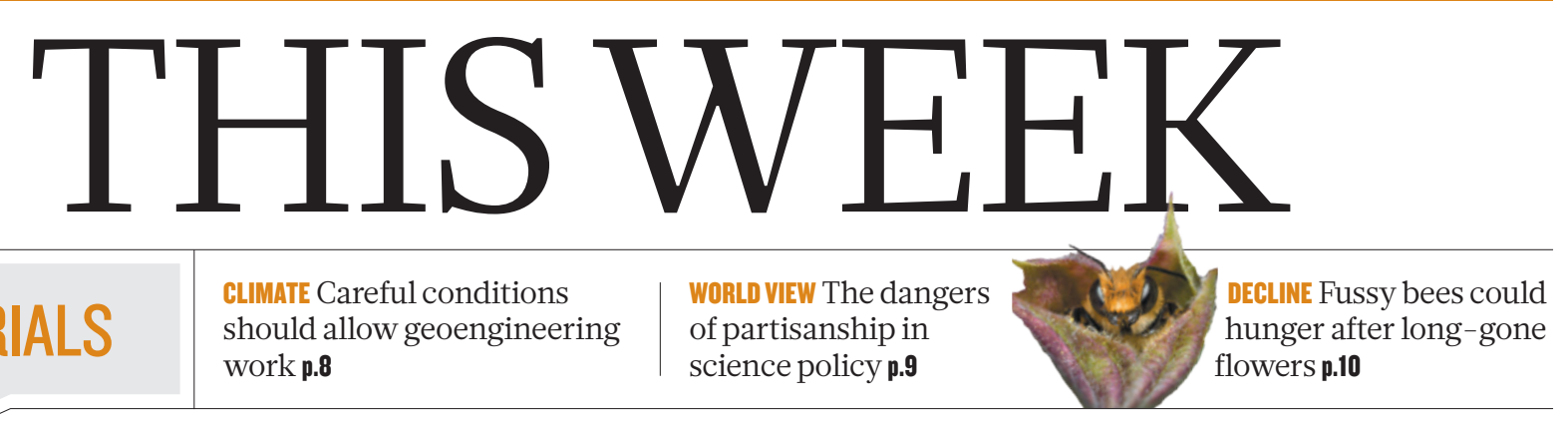

EDITORIALS should allow geoengineering work p.8

\title{
The uncertain dash for gas
}

\section{The United States and other countries have made huge investments in fracking, but forecasts of production may be vastly overestimated.}

A decade ago, fracking was a misprint. Now, hydraulic fracturing is heralded as the future of energy supplies. Leading the way is the United States, which is tapping its rich shale deposits to produce more natural gas than at any other time in its history. The International Energy Agency projected in November that global production of shale gas would more than triple between 2012 and 2040, as countries such as China ramp up fracking of their own shale formations.

How much gas and oil is down there? Predictions about future shortages and abundances of various fuels are tricky, because although the geological presence of resources can be surveyed to some degree, how much would be profitable to extract is a moving target. Academic journals are filled with earnest projections about future energy dynamics, which usually turn out to be wildly inaccurate. Even worse, governments and companies wager billions of dollars on dubious bets. This matters because investment begets further investment. As the pipework and pumps go in, momentum builds. This is what economists call technology lock-in.

This week, Nature presents previously unpublished data suggesting that the lock-in of technology into shale-gas production may be a riskier bet than previously realized, at least in the United States. Nature has obtained detailed US Energy Information Administration (EIA) forecasts of production from the nation's biggest shale-gas production sites. These forecasts matter because they feed into decisions on US energy policy made at the highest levels. Crucially, they are much higher than the best independent academic estimates.

The full story is contained in a News Feature on page 28. The conclusion is that the US government and much of the energy industry may be vastly overestimating how much natural gas the United States will produce in the coming decades.

The EIA projects that production will rise by more than $50 \%$ over the next quarter of a century, and perhaps beyond, with shale formations supplying much of that increase. But such optimism contrasts with forecasts developed by a team of specialists at the University of Texas, which is analysing the geological conditions using data at much higher resolution than the EIA's. The Texas team projects that gas production from four of the most productive formations will peak in the coming years and then quickly decline. If that pattern holds for other formations that the team has not yet analysed, it could mean much less natural gas in the United States' future.

Like all energy forecasts, the lower projections from the Texas team could turn out to be inaccurate. Technological advances in the next few decades could open up more resources at lower costs, driving US production even higher than the EIA has predicted. But it is also possible that the Texas forecasts are too high, and that gas production will fall off even faster than the team suggests.

The one certainty here is that the United States and other nations have invested relatively little in tracking and assessing their natural resources. The EIA has a total budget of US\$117 million, less than the value of one

day's gas production from the country's shale formations. The agency's budget has increased in recent years, but US natural-gas production has grown much more rapidly. There are now tens of thousands of wells tapping shale formations, and thousands more are started each year.

US federal and state governments have also failed to keep up with environmental concerns associated with fracking of shale formations for gas. For each well, drillers use tens of millions of litres of

"Nations

have invested relatively little in tracking and assessing their natural resources." research has found evidence of contamination associated with shalegas production. Similar environmental problems plague fracking of shale deposits for oil, which has led to a sharp rise in US petroleum production in the past five years. And then there is the bigger picture: the extra greenhouse-gas emissions that come from new sources of fossil fuels.

Fracking has momentum. It will probably continue to grow to become an important part of the energy mix in many parts of the world. But for strategic, economic and environmental reasons, all involved should take a hard look at the numbers.

\section{Harsh reality}

\section{Two reports highlight the plight of postdocs on both sides of the pond aiming for academia.}

$\mathrm{W}$ hen hundreds of UK scientists were asked in a recent exercise to describe high-quality scientific research, the most popular word that they suggested was "rigorous". Most were probably referring to its dictionary definition as "extremely thorough and careful". But more than a few must have been aware that the word has some other, equally valid, synonyms: rigidly severe, harsh, tough.

Good science is tough. But is it also harsh and severe? And if so, does it need to be? At what point do the legitimate demands of competitive academic research tip into a demoralizing lack of job security and intolerable pressure? It has been said before, not least in these pages, but two reports published this week on either side of the Atlantic highlight perhaps the most common pinch point: the postdoctoral years. 